\title{
Quality Improvement of Iron Ore Jasper by Selective Milling
}

\author{
Erivelto Luís de Souza ${ }^{1}$, Orimar Batista dos Reis ${ }^{2} \&$ Denise Fonseca Pereira ${ }^{3}$ \\ ${ }^{1}$ DTECH/CAP/UFSJ, Brazil \\ ${ }^{2}$ CODAMET/IFMG-OP, Brazil \\ ${ }^{3}$ UNIPAC-Lafaiete, Brazil \\ Correspondence: Erivelto Luís de Souza, Erivelto Luís de Souza, DTECH/CAP/UFSJ, Brazil. E-mail: \\ souza.erivelto@ufsj.edu.br
}

Received: September 25, 2017 Accepted: November 22, 2017 Online Published: November 25, 2017

doi:10.5539/emr.v7n1p10 URL: http://doi.org/10.5539/emr.v7n1p10

\begin{abstract}
One of the most important factors during the process of comminution of minerals is their power consumption rate, which is determined by calculating the WI (work index), which in short is to analyze the amount of $\mathrm{kWh}$ consumed per ton of material, to reach a certain particle size and achieve the desired. Along with the quality of the ore is defined and use the classification of the ore. Ores of jaspelite type, high hardness, and with lower iron content $60 \%$ with silica content above $10.5 \%$, tends to be considered economically unsuitable for merger cases in the Brazilian market. The work presented here consists of a technique that acts by transforming this type of ore at an acceptable quality product and with a lower power consumption than the previously calculated by WI analysis. The procedure presented here recovers a quantity of more than $75 \%$ by weight, taking an ore $56 \% \mathrm{Fe}$, for an average content of $65 \% \mathrm{SiO}_{2}$ and lowering the $10 \%$ to $4.5 \%$. Although reducing by $50 \%$ the amount of phosphorus present. The procedure presented here using known methods, but with a variation with respect to the operation, which gives you innovative character, acting together with a selective screening.
\end{abstract}

Keywords: selective milling, Jasper Ore, quality improvement

\section{Introduction}

\subsection{The Problem}

Iron ore coming from Corumbá, Brazilian Middle West region, are founded in many ways, lump, medium grained and jaspelitos. The latter, even with a significant iron content, present in coarse particle size and silica layer interleaved and some cases even higher iron content with "pockets" (or Jaspers) of silica. The presence of intercalated material and the size of the material leads to the need for treatment for mechanical processing of this ore.

The material studied initially presented a WI curve leading to an average of $18 \mathrm{kWh} / \mathrm{t}$ of processed material. At levels ranging is from $64 \%$ to $48 \%$ of $\mathrm{Fe}$, with the silica ranging from $7.5 \%$ to $12.5 \%$, and phosphorus often in the range around $0.16 \%$. The grinding has become a problem because the fines generated were high and with great loss of metal content. The study here presented haves the focus in the reduction of power consumption and increasing the quality of the iron ore.

The principles that define this work are the reduction of power consumption by the intermittent milling, interleaved with granulometric separation. Which leads to better quality material and energy consumption within the acceptable operating range.

The results obtained are in agreement with the physical and mineralogical properties of the treated ore. Based on these factors, it was possible to find the adequate time and consumption range for the production of pellet feed with this ore to be viable qualitatively and quantitatively.

According to Shi \& Xie (2016), the use of energy in the grinding process is strictly related to the shape of the ground particles and to the interaction of these particles with the grinding bodies.

\subsection{Reduction of Energy Consumption}

The results obtained are in agreement with the physical and mineralogical properties of the treated ore. Based on these factors, it was possible to find the adequate time and consumption range for the production of pellet feed 
with this ore to be viable qualitatively and quantitatively. The decrease in consumption allows operations with greater environmental sustainability.

In his article on energy parameters in grinding, Gupta \& Sharma (2014) shows that the distribution of particles is a fundamental factor for controlling the Work Index. The more varied the grain size range, the more energy is lost in grinding. In another paper, Gupta, V.K. (2017), shows that the longer the finer particles remain in the grinding process, the more they act as energy dispersers, hampering the efficiency of the milling process.

\subsection{Relevant Scholarship}

Curry, Ismay \& Jameson (2014) in their paper describe that the relation of the milling process always comes up against the issue of operating cost. The analysis of each step is strictly important to define the effect of operational quality. Still second Shi and Xie (2016), each analysis is based in an individual observation, for each different ore treated. In the mineral research a lot of iron ores are studded to found the best relation of energy and production.

Lessarda, Bakkerb \& McHugha (2014) describe in their work that the reduction of energy consumption is an important factor in the analysis of Clean Development Mechanisms. If the processing of ores could be occur with less energy of traditional, the best quality of product will be founded, and better sustainable conditions will be practiced.

\subsection{State Hypotheses and Their Correspondence to Research Design}

The analysis of the milling time, according to the Bond criteria, proved the hardness of the analyzed material, as can be seen in Figure 1.

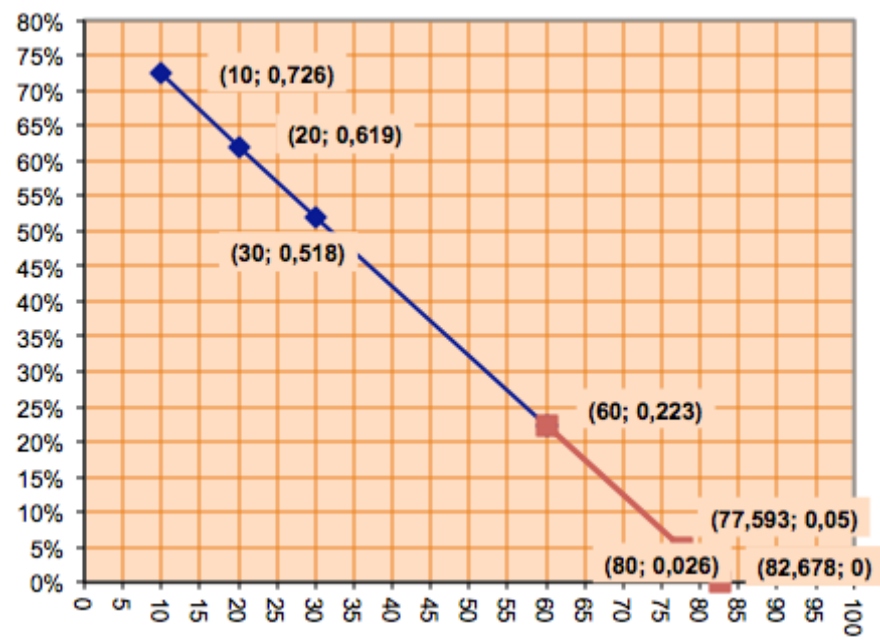

Figure 1. Time analysis for definition of work index (X-axis: time in minutes; Y-axis: \% pass by)

Observing the result of the granulometric distribution process after grinding, it was expected that the material retained in the first milling would be more fragile and, therefore, would suffer an easier comminution. However, what was noticed in the second milling was a material retained larger than the previous one, leading to the conclusion that a more fragile part of the ore had been initially split, remaining in the second stage the most resistant part. This analysis was due to the simple fact that the mineral form does not suffer as much as with metals, which would not justify its greater resistance in the second grinding. How is showed in the Figure 2. 


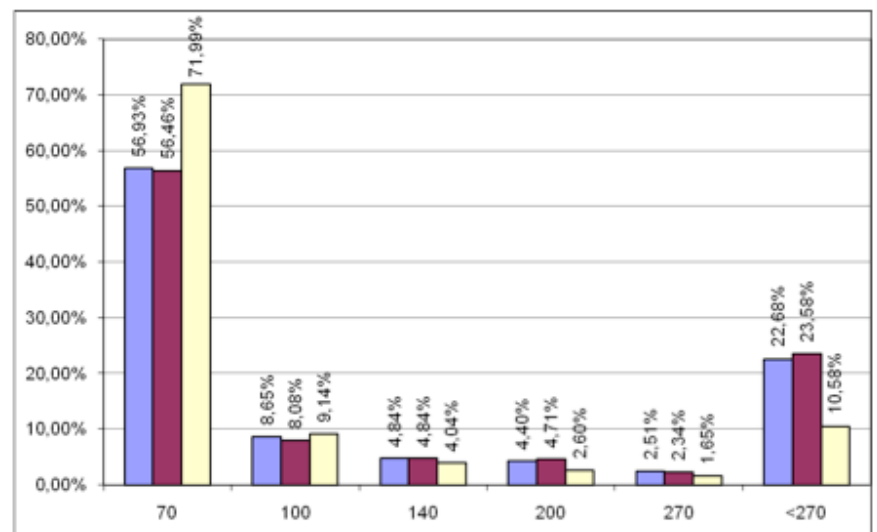

Figure 2. Graph showing the comparison between the particle size distribution of the primary milling (red and blue) and the second milling (yellow)

\subsection{Studied Materials}

The material used was the jasper ore with low iron content. The prevailing geology in the region of the city of Corumbá, Mato Grosso do Sul, Brazil, can be seen in the Figure 3.

The geology of the western region of Brazil, specifically the city of Corumbá, Mato Grosso do Sul, is predominantly composed of a rocky complex called Urucum Massif. Famous for being the largest and most culminating rock formation of the region, with an altitude of 1065 meters. Because of the nature of its rocks, the Urucum Massif has large mineral reserves, which pyrolusite and cryptomelane (has the largest reserve of Brazil and one of the world's largest and can be extracted 30 million tons) and specially a type iron hematite and itabirite (third largest in Brazil), non-metamorphosed, jaspelite ore, object of this work. The ores used in this work is the jaspelite ore, with high hardness and medium iron content. Showed in Figure 4.

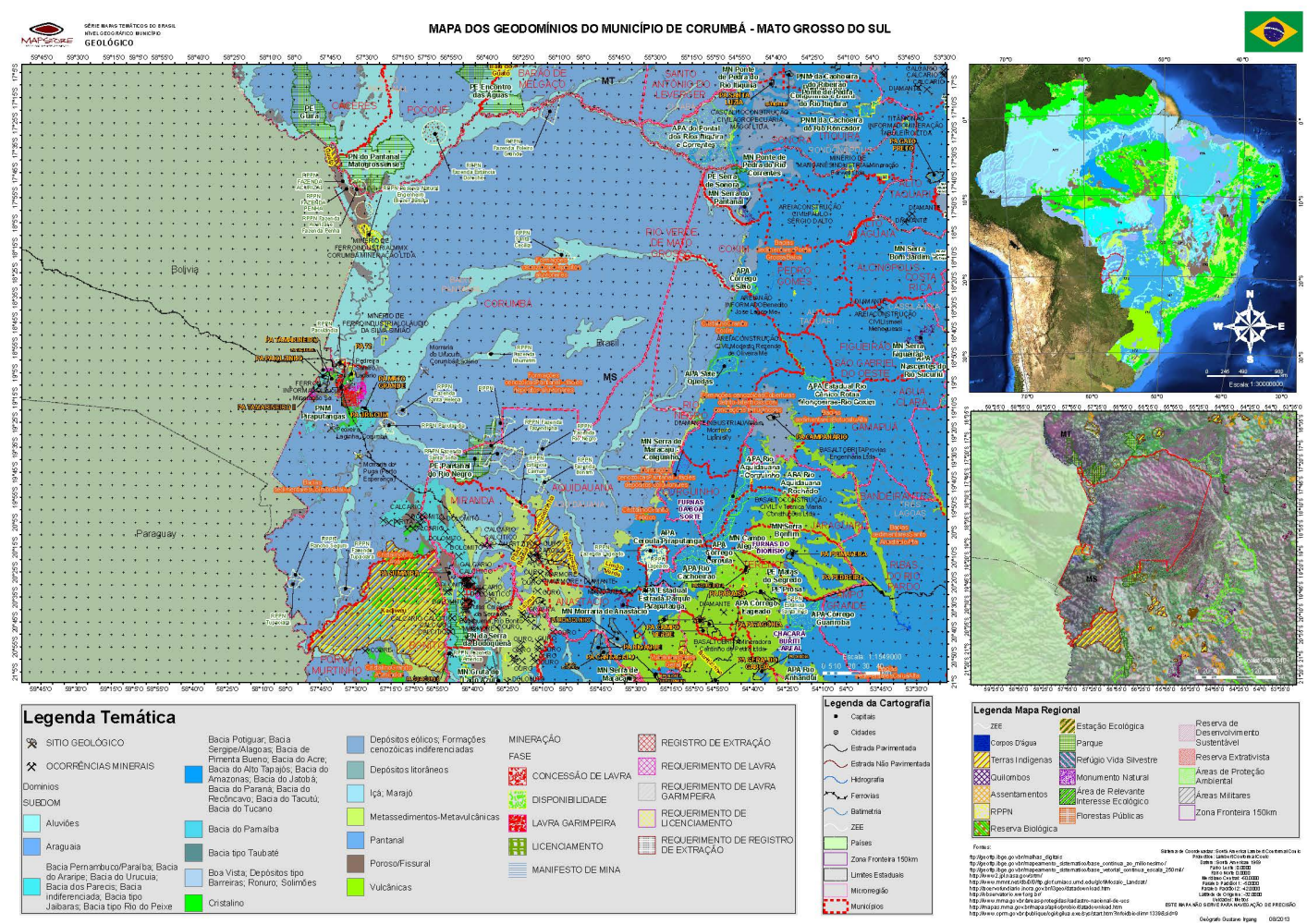

Figure 3. Map of geological domains of the city of Corumbá, MS, Brazil 


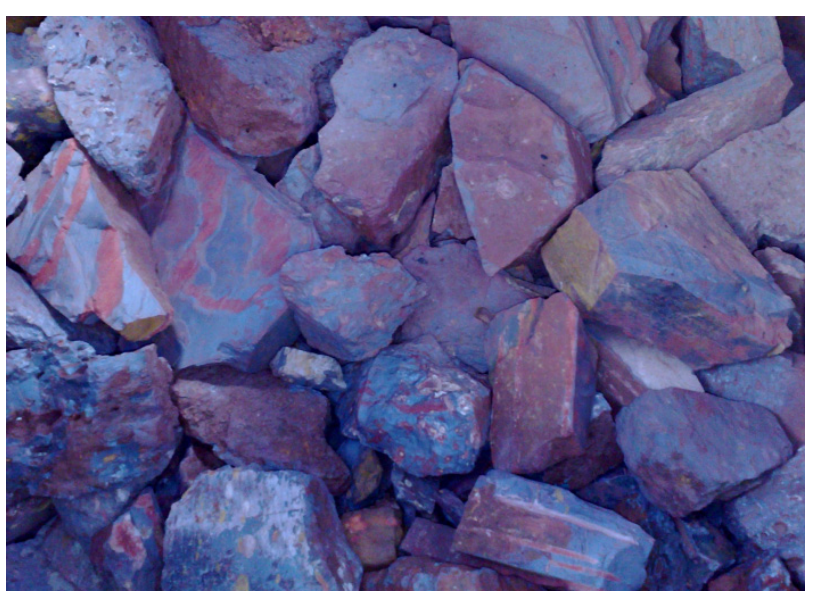

Figure 4. Sample of the jasper used in the tests

The analyzed ore found in this region has a low iron content compared with the equivalent most used iron ores. Even when its content reaches range considered applicable to economic viability, the hardness and high Work Index makes it initially impractical to use for processing the concentration of the metallic content. The Table 1 illustrates the average analysis of the studied ore.

Figures 3 and 4 illustrate, respectively, the Work Index analysis of the work done for this type of ore and the granulometric analysis by milling time for this ore. The test determines the Work Index or grindability (Work Index) for ball mills. The BWI is used with the third

Table 1. Table showing the initial composition of the tested material

\begin{tabular}{llllllllll}
\hline W.I. & $\mathrm{Fe}$ & $\mathrm{SiO}_{2}$ & $\mathrm{Al}_{2} \mathrm{O}_{3}$ & $\mathrm{P}$ & $\mathrm{Mn}$ & Limonite & Density & Humidity & L.F. \\
\hline 17.75 & $48.40 \%$ & $11.27 \%$ & $2.59 \%$ & $0.184 \%$ & $0.010 \%$ & $2.16 \%$ & 2.15 & $3.8 \%$ & $3.3 \%$ \\
\hline
\end{tabular}

\section{Method}

\subsection{Analysis of the Jasper Ores Milling}

The analysis of the behavior of the material during the milling led to the calculation of average rate of W.I. around $17.8 \mathrm{kWh} / \mathrm{t}$, led the concentration of this product not economical. How is showed in Figure 1.

According to Nadolski, Klein, Kumar and Davaanyam (2014), the equation that Bond developed for this calculation was:

$$
\mathrm{W}=\frac{\sqrt{100} \cdot \mathrm{W}_{\mathrm{i}}}{\sqrt{\mathrm{P}}}-\frac{\sqrt{100} \cdot \mathrm{W}_{\mathrm{i}}}{\sqrt{\mathrm{F}}}
$$

Where

$\mathrm{W} \rightarrow$ predicted mill energy consumption, in $\mathrm{kWh} / \mathrm{st}$

$\mathrm{W}_{\mathrm{i}} \rightarrow$ Work Index, in $\mathrm{kWh} / \mathrm{st}$

$100 \rightarrow 100 \mu \mathrm{m}$, which is the product size in the definition of Work Index

$\mathrm{P}, \mathrm{F} \rightarrow 80 \%$ passing sizes, in $\mu \mathrm{m}$, of the feed $(\mathrm{F})$ and product $(\mathrm{P})$

This equation is also commonly written as

$$
\mathrm{W}=10 . \mathrm{W}_{\mathrm{i}}\left(\frac{1}{\sqrt{\mathrm{P}}}-\frac{1}{\sqrt{\mathrm{F}}}\right)
$$


However, the analysis of the background grinding, created a highlight atypical behavior of the sample. It was expected ease in secondary crushing, however, the sample recovered, above 70\#, it became more difficult to grind than the initial sample. How is showed in Figure 2.

After milling it was found that the material was difficult to be ground. So one could deduce that two types of materials were being processed, the softer first and harder second. As showed in Figure 5.

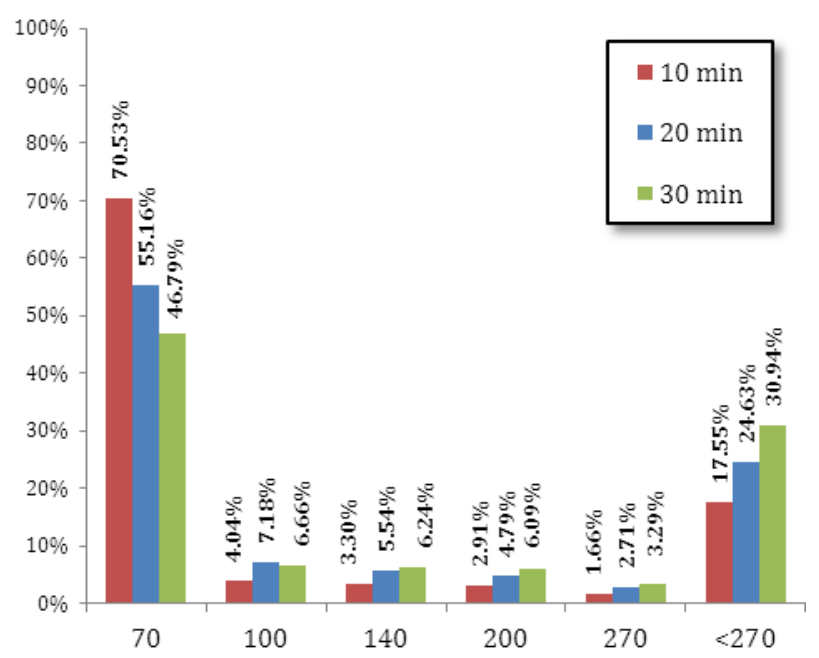

Figure 5. Comparative graph of the effect of milling time on the comminution of the samples

Table 2. The relationship between the grinding time, content and weight distribution of the sample [1]

\begin{tabular}{lllllll}
\hline Time & Size & R. Mass & $\mathbf{\% F e}$ & $\mathbf{\% S i O}_{\mathbf{2}}$ & $\mathbf{\% A l}_{\mathbf{2}} \mathbf{O}_{\mathbf{3}}$ & $\mathbf{\% \mathbf { P }}$ \\
\hline $10^{\prime}$ & $70 \#$ & $70.5 \%$ & $68.350 \%$ & $2.973 \%$ & $0.340 \%$ & $0.080 \%$ \\
$10^{\prime}$ & $100 \#$ & $4.0 \%$ & $65.817 \%$ & $4.220 \%$ & $0.688 \%$ & $0.086 \%$ \\
$10^{\prime}$ & $140 \#$ & $3.3 \%$ & $64.220 \%$ & $5.006 \%$ & $0.907 \%$ & $0.090 \%$ \\
$10^{\prime}$ & $200 \#$ & $2.9 \%$ & $64.138 \%$ & $6.720 \%$ & $1.261 \%$ & $0.090 \%$ \\
$10^{\prime}$ & $270 \#$ & $1.7 \%$ & $64.080 \%$ & $7.936 \%$ & $1.512 \%$ & $0.090 \%$ \\
$10^{\prime}$ & $<270 \#$ & $17.554 \%$ & $\mathbf{5 4 . 4 6 2 \%}$ & $\mathbf{6 . 6 6 4 \%}$ & $\mathbf{7 . 3 5 2} \%$ & $\mathbf{0 . 3 8 2 \%}$ \\
$30^{\prime}$ & $70 \#$ & $46.787 \%$ & $67.570 \%$ & $2.588 \%$ & $0.265 \%$ & $0.060 \%$ \\
$30^{\prime}$ & $100 \#$ & $6.658 \%$ & $66.184 \%$ & $3.821 \%$ & $0.150 \%$ & $0.072 \%$ \\
$30^{\prime}$ & $140 \#$ & $6.240 \%$ & $65.310 \%$ & $4.599 \%$ & $0.077 \%$ & $0.080 \%$ \\
$30^{\prime}$ & $200 \#$ & $6.088 \%$ & $65.907 \%$ & $4.975 \%$ & $0.623 \%$ & $0.086 \%$ \\
$30^{\prime}$ & $270 \#$ & $3.285 \%$ & $66.330 \%$ & $5.241 \%$ & $1.010 \%$ & $0.090 \%$ \\
$30^{\prime}$ & $<270 \#$ & $30.943 \%$ & $\mathbf{6 2 . 0 2 8 \%}$ & $\mathbf{5 . 5 0 3 \%}$ & $\mathbf{4 . 6 5 4 \%}$ & $\mathbf{0 . 2 8 4} \%$ \\
\hline
\end{tabular}

The chemical particle size analysis (Table 2) shows levels of up to $68 \% \mathrm{Fe}$ in the retained, indicating that silica present in the ore was crushed first. The total energy can be founded using the comminution theory of Bond to calculate what is the net power requirements for grinding. However, several correction factors may have to be applied.

\subsection{Analysis Procedure}

The analysis of the milling time shows that the material was concentrated, however, also be realized that the iron content in the thin particles was increased with increasing milling time. The Table 2 shows that more time grinding increases the iron content in the fine and less of impure. 


\subsection{Equipment and Process}

This process works with a processing line, created to return the grinding material above 100\# for milling; discarding material undersize 270\#; and directing the material in the range between 270\# and 100\# as product, which corresponding to an average of $70 \%$ of the mass of the milling feed, as showed in Figure 6.

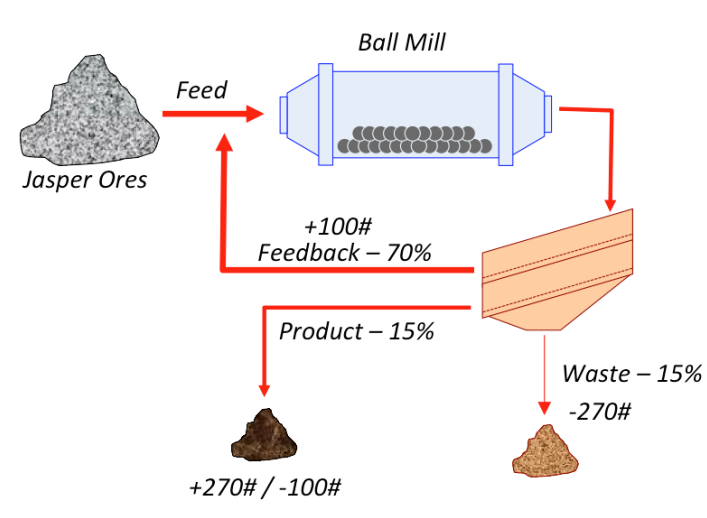

Figure 6. Flow chart of selective milling

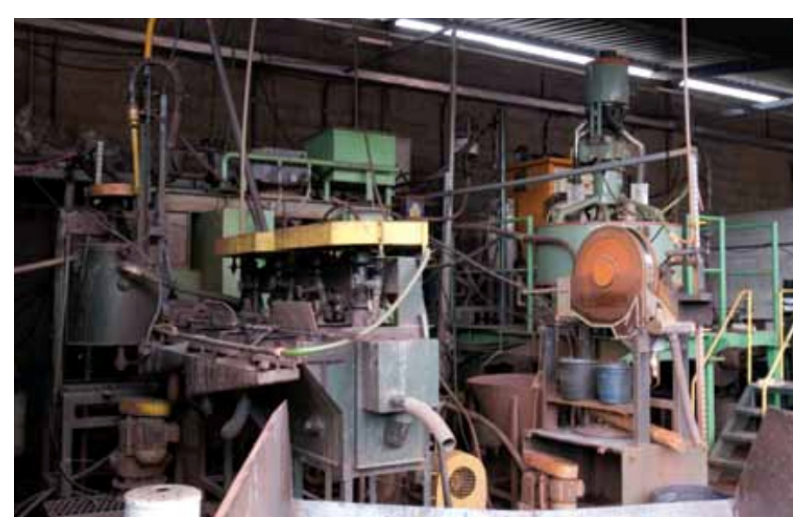

Figure 7. Adjustable plant used for testing in Gorceix Foundation

\section{Results and Discussion}

\subsection{Quality of Product}

A longer milling reduced the iron content in the retained it increased and the thin, allowing to deduce that the silica was acting as an abrasive, leading to iron ore fines, but this abrasion also carried in the first instance phosphorus for fine, reducing it in retained.

To then get a retained with a high iron content, good recovery and decrease in phosphorus, 20 minutes mills were made, separating the part below $270 \#$, passing by $15 \%$ every grinding, where the mass retained $100 \#$ was $70 \%$ allowed in the context of four straight milling, 20 ' in the range $+270 \#-100 \#$ to recover more than $68 \%$ by weight, with an enrichment of the metallic content of 48 to $67 \% 5 \%$. Fall of $10 \%$ silica content to about $2.28 \%$. Phosphorus reduction from $0.18 \%$ to $0.076 \%$. This is all about $11.85 \mathrm{kWh} / \mathrm{t}$. This process makes this ores viable for commercial use.

Table 3. The final results after selective milling

\begin{tabular}{llllllllll}
\hline W.I. & $\mathrm{Fe}$ & $\mathrm{SiO}_{2}$ & $\mathrm{Al}_{2} \mathrm{O}_{3}$ & $\mathrm{P}$ & $\mathrm{Mn}$ & Limonite & Density & Humidity & L.F. \\
\hline 11.85 & $68.5 \%$ & $2.28 \%$ & $0.59 \%$ & $0.076 \%$ & $0.016 \%$ & $1.04 \%$ & 3.65 & $1.8 \%$ & $2.1 \%$ \\
\hline
\end{tabular}

\subsection{Efficiency in Use of Time and Milling Capacity}

Each intermediate stage, after 20 minutes of grinding, only $70 \%$ of the mass is directed to the next step, the power consumption is significantly reduced in direct relation to milling for 80 minutes.

\section{Discussion}

After the analysis of the results, it was possible to notice that the anticipated silica fragmentation, in comparison with the hematite, allowed the stepwise grinding to avoid losses of metallic content in the discard, generated by the abrasiveness of the fine silica generated, as well as significantly decreased the consumption of energy for the process. Energy was only consumed in the granulometry that was above the desired size.

With this, the process enabled the recovery of discard piles that had initially been disregarded for the production of pellet feed.

\section{Acknowledgement}

My sincere thanks to FAPEMIG, CNPq, DTECH/CAP/UFSJ, Gorceix Foundation and to my colleagues, partners 
in this work.

\section{References}

Becker, C. (2016). http://carlosbecker.com.br/site/peneira-giratoria/, accessed on 2nd May, 2016.

Chaves, A. P., Johnson, B., Fernandes, F., Sirotheau, G. J. C., Lima, M. H. R., Barreto, M. L., Bôas, R. C. V., \& Nahass, S. (2001). Mineração e Desenvolvimento Sustentável: Desafios para o Brasil. CETEM/MCT, Rio de Janeiro, RJ, Brasil, 2001.

Curry, J. A., Ismay, M. J. L., \& Jameson, G. J. (2014). Mine operating costs and the potential impacts of energy and grinding. Minerals Engineering, 56, 70-80. https://doi.org/10.1016/j.mineng.2013.10.020

Figueira, H. V. O., Almeida, S. L. M., \& Luz, A. B. (2004). Cominuição. CT2004-182-00, CETEM, Rio de Janeiro, RJ, Brazil, 2004.

Gupta, V. K. (2017). Effect of Size Distribution of the Particulate Material on the Specific Breakage Rate of Particles in Dry Ball Milling. Powder Technology, 305, 714-722. https://doi.org/10.1016/j.powtec.2016.10.075

Gupta, V. K., \& Sharma, S. (2014). Analysis of ball mill grinding operation using mill power specific kinetic parameters. Advanced Powder Technology, 25(2), 625-634. https://doi.org/10.1016/j.apt.2013.10.003

Lessarda, J., Bakkerb, J., \& McHugha, L. (2014). Development of Ore Sorting and Its Impact on Mineral Processing Economics. Minerals Engineering, 65, 88-97. https://doi.org/10.1016/j.mineng.2014.05.019

Luz, A. B., \& Lins, F. A. F. (2004). Tratamento de Minérios. CT2004-179-00, CETEM, Rio de Janeiro, RJ, Brazil, 2004.

Mapstore. (2016). http://mapstore.eco.br/image/data/mapas/geologia/geodominios/municipios/, accessed on 2nd May, 2016.

Nadolski S., Klein, B., Kumar A., \& Davaanyam, Z. (2014). An Energy Benchmarking Model for Mineral Comminution. Minerals Engineering, 65, 178-186. https://doi.org/10.1016/j.mineng.2014.05.026

Rosa, G. M., \& Luz, J. A. M. (2012). Simulação de Moagem Mista por Rede Neural Artificial. R. Esc. Minas, 65(2), 247-255. https://doi.org/10.1590/S0370-44672012000200014

Shi, F., \& Xie, W. (2016). A specific energy-based ball mill model: From batch grinding to continuous operation. Minerals Engineering, 86, 66-74. https://doi.org/10.1016/j.mineng.2015.12.004

Souza, E. L., Gomes, G. S. L., Oliveira, L. J. M., \& Pereira, D. F. (2014). Melhora da Qualidade de um Minério Jaspelítico por Moagem Seletiva. 21th CBECiMat, Cuiabá, MT, Brazil, 2014.

Souza, E. L., Reis, O. B., Borges, L. C., \& Pereira, D. F. (2016). Mineral Processing. Quality Improvement of an Iron Ore Jasper by Selective Milling. 24th World Mining Congress, 2016, CDU: 622/5:502/504, pp. 237-244.

U.S. Environmental Protection Agency, Office of Solid Waste, Special Waste Branch. (1994). Extraction and Beneficiation of Ores and Minerals. 401 M Street, SW, Washington, DC 20460, 1994.

Williams, O., Eastwick, C., Kingman, S., Giddings, D., Lormor, S., \& Lester, E. (2015). Investigation into the applicability of Bond Work Index (BWI) and Hardgrove Grindability Index (HGI) tests for several biomasses compared to Colombian La Loma coal. Minerals Engineering, 158, 379-387. https://doi.org/10.1016/j.fuel.2015.05.027

\section{Copyrights}

Copyright for this article is retained by the author(s), with first publication rights granted to the journal.

This is an open-access article distributed under the terms and conditions of the Creative Commons Attribution license (http://creativecommons.org/licenses/by/4.0/). 